\title{
Lactic acid bacteria with cholesterol-lowering properties for dairy applications: In vitro and in situ activity
}

\author{
C. Albano, ${ }^{*}$ S. Morandi, ${ }^{*}$ T. Silvetti, ${ }^{*}$ M. C. Casiraghi, $†$ F. Manini, ${ }^{*}$ and M. Brasca* \\ *Institute of Sciences of Food Production, National Research Council, Via Celoria 2, 20133 Milan, Italy \\ †Department of Food, Environmental and Nutritional Science, University of Milan, Via Celoria 2, 20133 Milan, Italy
}

\begin{abstract}
Cholesterol-lowering activity is one of the most promising properties of lactic acid bacteria with probiotic characteristics. In the present study, 58 potentially probiotic lactic acid bacteria were tested for their ability to survive in vitro digestion and reduce cholesterol in a medium containing cholesterol and bile acids. The best-performing strains (Lactobacillus casei VC199, Lactobacillus paracasei ssp. paracasei SE160 and VC213, Lactobacillus plantarum VS166 and VS513, Enterococcus faecium VC223, and Enterococcus lactis BT161) resulted in a 42 to $55 \%$ reduction of the cholesterol level in broth and were further tested in cheese manufacture. The cholesterol content in all the cheeses decreased with ripening. All the strains were present in the cheese at levels higher than $10^{7} \mathrm{cfu} / \mathrm{g}$ until $60 \mathrm{~d}$ of ripening, the highest reductions (up to 23\%) being obtained when $L b$. paracasei ssp. paracasei $\mathrm{VC} 213$ and E. lactis BT161 were added during the cheese-making. The adjunct cultures had no negative effect on the sensory characteristics of the cheese. Thus, these strains with proven in vitro properties are good candidates for novel probiotic-containing formulations and could be used to functionalize foods such as dairy fermented products.
\end{abstract}

Key words: Lactobacillus, Enterococcus, cholesterol, cheese

\section{INTRODUCTION}

Coronary heart disease is the main cause of death in many countries around the world, and the magnitude of cardiovascular diseases continues to accelerate globally (Liu, 2007; Townsend et al., 2016). The risk of heart attack is 3 times higher in people with hypercholester-

Received May 22, 2018.

Accepted August 3, 2018.

${ }^{1}$ Corresponding author: milena.brasca@ispa.cnr.it olemia than in those with normal blood lipid profiles (Kumar et al., 2012). Some studies have shown that even a small (1\%) reduction in serum cholesterol could reduce the risk of coronary heart disease by 2 to $3 \%$ (Manson et al., 1992; Liong and Shah, 2005). Pharmacological agents that effectively reduce cholesterol levels are available for the treatment of high cholesterol; however, they are expensive and are known to have side effects (Bliznakov, 2002; Kumar et al., 2012).

The World Health Organization delineated that unhealthy diets, such as those high in saturated fat, trans fat, cholesterol, and salt and low in fruit, vegetables, and fish, increase the risk of cardiovascular diseases (Puska et al., 2011). Plant stanols and sterols, which lower serum concentrations of cholesterol, have been incorporated into foods, but they are expensive (Law, 2000). Over the years, the probiotic activity of lactic acid bacteria (LAB) has been studied (Collins, 2014), and $\mathrm{LAB}$ have been associated with improved lactose intolerance, increased natural resistance to infectious disease in the gastrointestinal tract, the suppression of cancer, and better digestion and skin health (Lye et al., 2010; Clarke et al., 2012; Kanmani et al., 2013; Zhong et al., 2014; Jeong et al., 2016). Moreover, Mann and Spoerry (1974) and Shaper et al. (1963) evidenced the hypocholesterolemic effects of a diet containing LAB strains, and it has been proven that some LAB can lower total cholesterol and low-density lipoprotein cholesterol levels (Zeng et al., 2010; Ishimwe et al., 2015). The LAB strains previously reported to possess cholesterol reduction ability belong to Lactobacillus casei (Klaver and Van Der Meer, 1993), Lactobacillus plantarum, Lactobacillus paracasei (Belviso et al., 2009), Lactococcus lactis (Kimoto et al., 2002), and Enterococcus faecium (Hlivak et al., 2005; Ayyash et al., 2018). Raw milk cheeses represent a notable source of wild LAB strains that can have health-promoting properties in addition to giving the cheese its unique characteristics (Brasca et al., 2016; Guarcello et al., 2016). Moreover, it is well documented that dairy products such as cheese and dairy-based desserts are excellent natural and cleanlabeled delivery systems for probiotic inclusion in the 
diet (Vinderola et al., 2000; Lollo et al., 2015; Dantas et al., 2016; Moura et al., 2016). Thus, LAB also represent a potential strategy to reduce cholesterol in foodstuffs. However, to date, very few attempts have been made to use LAB to reduce the cholesterol in foods, particularly in dairy products, as a potential alternative to the more expensive chemical and physical processes, which can lead to texture alteration and flavor removal (Larsen and Froning, 1981; Aloğlu and Öner, 2006; Han et al., 2007; Belviso et al., 2009).

Thus, there is a need to focus on the scientific exploration of natural low-fat foods and on products that may be able to lower the serum cholesterol level extensively with minor or no side effects. The development of products with health benefits is a key research priority for the food sector, providing a powerful opportunity for the dairy industry as the global market of functional foods is expected to grow rapidly over the coming years.

The aim of the present work was to assay $58 \mathrm{LAB}$ strains for their ability to remove cholesterol during growth using in vitro assessment to further test for the best-performing strains for their ability (1) to survive gastrointestinal conditions, (2) to survive in cheese during the ripening time at adequate levels to provide beneficial effects for consumers, and (3) to reduce cholesterol to a great extent in cheese.

\section{MATERIALS AND METHODS}

\section{Bacterial Strains, Culture Conditions, and Microbiological Analyses}

A total of 58 LAB strains isolated from traditional Italian cheeses, obtained from the National Research Council Institute of Sciences of Food Production (Milan Italy) collection, were considered. The strains belonged to different species of major interest as culture starters or considered to be potentially beneficial: $7 \mathrm{Lb}$. casei, 27 Lb. paracasei ssp. paracasei, 15 Lb. plantarum, 7 Lc. lactis ssp. lactis, 1 E. faecium, and 1 Enterococcus lactis (Supplemental Table S1; https://doi.org/10.3168/jds .2018-15096). The strains were previously identified by partial $16 \mathrm{~S}$ ribosomal DNA sequence analysis as described by Morandi et al. (2015). The 2 enterococci strains had previously been tested for antibiotic resistance and did not harbor any of the virulence genes reported by the European Food Safety Authority (EFSA) for the safety assessment of E. faecium (EFSA Panel on Additives and Products or Substances Used in Animal Feed, 2012; Morandi et al., 2013, 2015).

The lactobacilli strains were maintained in de Man, Rogosa and Sharpe (MRS) broth (Biolife, Milan, Italy), whereas lactococci and enterococci were cultured in M17 broth (Biolife). For experimental use, working cultures were subcultured twice in their respective broths for activation. Then, they were taken at the end of the exponential phase of growth at cell densities of approximately $10^{9} \mathrm{cfu} / \mathrm{mL}$ and inoculated at $1 \%$ (vol/ vol). In the experimental trials the bacterial counts were evaluated using MRS agar under anaerobic conditions (AnaerocultA, Merck, Darmstad, Germany) at $37^{\circ} \mathrm{C}$ for $72 \mathrm{~h}$ for lactobacilli, whereas M17 agar and kanamycin aesculin azide agar (Scharlau Science, Barcelona, Spain) at $37^{\circ} \mathrm{C}$ for $48 \mathrm{~h}$ were used for lactococci and enterococci, respectively.

\section{Culture Conditions for Determination of Cholesterol Removal from Media In Vitro}

Modified broth [MRS or M17 supplemented with $0.2 \%$ (wt/vol) sodium thioglycolate (Sigma Chemical Co., St. Louis, MO] as an oxygen scavenger (Usman and Hosono, 1999) was used to screen the cultures for cholesterol uptake. The broths were further supplemented with $0.3 \%$ (wt/vol) oxgall and a water-soluble form of cholesterol (polyoxyethanyl-cholesteryl sebacate; Cholesterol-PEG 600, Sigma). The final cholesterol concentration in the medium was $120 \mu \mathrm{g} / \mathrm{mL}$. The cultures were inoculated at $1 \%(\mathrm{vol} / \mathrm{vol})$ and incubated at $30^{\circ} \mathrm{C}$ for $24 \mathrm{~h}$ in anaerobic jars in triplicate. Uninoculated sterile broth was used as the control (Pereira and Gibson, 2002).

\section{Survival in Simulated In Vitro Digestion}

The transit tolerance was performed in vitro by exposing the milk fermented by the single strains through the simulated gastric juice and simulated small intestinal juice successively, as described by Vizoso Pinto et al. (2006) and Nueno-Palop and Narbad (2011). The LAB strains were inoculated at a level of $1 \%$ in reconstituted sterile nonfat dry milk ( $10 \% \mathrm{wt} / \mathrm{vol}$; Sacco s.r.l., Cadorago, Italy) and grown overnight at $37^{\circ} \mathrm{C}$. Ten grams of the fermented milk was diluted $1 / 10$ in PBS. To simulate the possible hydrolysis of bacteria in the human oral cavity, lysozyme (Bioseutica, Lugano, Switzerland) was added to a final concentration of $100 \mathrm{mg} / \mathrm{kg}$. The sample was incubated for $5 \mathrm{~min}$ at $37^{\circ} \mathrm{C}$; then, to simulate an artificial gastric fluid, $\mathrm{pH}$ was adjusted to 3.0, and pepsin (Sigma) was added to a final concentration of $5 \%$ (wt/vol). The mix was incubated at $37^{\circ} \mathrm{C}$ for $90 \mathrm{~min}$. To create the small intestine conditions, the sample was adjusted to $\mathrm{pH} 6.0$ and solutions of Pancreatin (Sigma) and bile salts (Oxgall, Fluka, St. Louis, MO) at final concentrations of 0.1 and $0.3 \%(\mathrm{wt} / \mathrm{vol})$, respectively, were added. Samples 
were incubated for $150 \mathrm{~min}$ at $37^{\circ} \mathrm{C}$. Changes in cell viability were monitored along the digestion pathway, specifically before and after oral, gastric, and intestinal digestion. An aliquot of the sample was serially diluted and then plated on MRS agar in triplicate. The plates were incubated aerobically for $48 \mathrm{~h}$ for enterococci and $72 \mathrm{~h}$ under anaerobic (AnaerocultA) conditions for lactobacilli. The cell counts were determined considering the volume variation due to $\mathrm{pH}$ adjustments and the subsequent samplings.

\section{Culture Conditions for Determination of Cholesterol Removal in Cheese}

The best-performing strains, showing the ability to reduce cholesterol in vitro more than $40 \%$ (arbitrarily chosen threshold), were further tested in cheese-making trials in addition to the starter culture. To prepare the inoculum for cheese-making, the strains were inoculated in UHT caprine milk, incubated at $30^{\circ} \mathrm{C}$ for 18 $\mathrm{h}$, and added to vat milk to a final concentration of approximately $10^{7} \mathrm{cfu} / \mathrm{mL}$.

\section{Cheese Manufacture}

Experimental cheese-making trials were conducted by Il Boscasso cheese factory (Ruino, Pavia, Italy). Each experiment consisted of a control vat and vats inoculated with single adjunct LAB cultures. Briefly, the vat containing $10 \mathrm{~L}$ of goat raw milk (3.5\% fat; wt/ wt) was warmed to $34^{\circ} \mathrm{C}$. A commercial freeze-dried thermophilic lactic culture including Streptococcus thermophilus and Lactobacillus delbrueckii ssp. bulgaricus (TC 00, Santamaria s.r.l., Burago di Molgora, Italy) was used as the starter culture in the cheese-making following the manufacturer's instructions. In addition, the experimental vats were inoculated with the single cholesterol-removing strains ( $L b$. casei VC199, Lb. paracasei ssp. paracasei $\mathrm{SE} 160$ and $\mathrm{VC} 213, L b$. plantarum VS166 and VS513, E. faecium VC223, and E. lactis BT161) at $10^{7} \mathrm{cfu} / \mathrm{mL}$. Fifteen minutes after the starter addition, calf rennet paste was added to the milk and incubated at $35^{\circ} \mathrm{C}$ for approximately 25 min. After the completion of curdling, the curd was cut to obtain grains of maize size and was stirred for about $10 \mathrm{~min}$. The curd was then distributed in circular shapes (12 cm in diameter) to allow whey drainage. After draining at 20 to $23^{\circ} \mathrm{C}$ for $20 \mathrm{~h}$, the cheese was dry salted on the surface with coarse-grained salt for 24 $\mathrm{h}$ on wooden boards and after a further $24 \mathrm{~h}$ ripened for up to $60 \mathrm{~d}$ at about 10 to $12^{\circ} \mathrm{C}$ with $90 \%$ relative humidity. Two cheese-making trials were performed for each test strain.

\section{Assessment of the Viability of Cholesterol-Removing Strains in Cheese}

Bacterial Isolation from Cheese Samples. The persistence in the cheeses of the selected LAB strains was assessed at each sampling point for up to $60 \mathrm{~d}$ of ripening by microbiological analysis. Ten grams of cheese produced with the addition of the selected strains was diluted in $90 \mathrm{~mL}$ of a $2 \%(\mathrm{wt} / \mathrm{vol})$ sterile $\mathrm{K}_{2} \mathrm{HPO}_{4}$ buffer solution (potassium hydrogen phosphate; Sigma) for $1 \mathrm{~min}$ in a Stomacher BagMixer (Interscience, St. Nom, France). The samples were serially diluted in quarterstrength Ringer's solution, and 1-mL aliquots were used to inoculate MRS agar $\mathrm{pH} 5.4$ under anaerobic conditions at $37^{\circ} \mathrm{C}$ for $72 \mathrm{~h}$ for the lactobacilli and kanamycin aesculin azide agar for enterococci. From each sample and at each ripening stage, 10 colonies showing the test strain colony morphology were selected and purified on homofermentative-heterofermentative differential agar (Biolife) and stored as stock cultures in $20 \%$ (vol/vol) glycerol at $-20^{\circ} \mathrm{C}$ for further examination.

DNA Extraction. The original strains used for milk inoculation and the isolates from the cheeses were grown overnight at $37^{\circ} \mathrm{C}$ in MRS broth (lactobacilli) or M17 broth (enterococci). Then, DNA was extracted using the Microlysis kit (Labogen, Rho, Italy), following the manufacturer's instructions.

Strain Typing and Traceability in Cheese by Randomly Amplified Polymorphic DNA Profile. To evaluate the implantation capacity of the cholesterol-lowering strains, the random amplified polymorphic DNA (RAPD) PCR analysis was used to characterize the isolates from the experimental cheeses. The RAPD PCR reactions were performed with primers M13 (5'-GAGGGTGGCGGTTCT-3'; McCabe et al., 1995). Grouping of the RAPD PCR profiles was obtained with the BioNumeric 5.0 software package (Applied Maths, Kortrjik, Belgium) using unweighted pair group method using arithmetic averages (UPGMA) cluster analysis. The reproducibility value of the RAPD PCR assay, calculated from 2 repetitions of independent amplification of the LAB type strains, was higher than $90 \%$. Thus, isolates showing a similarity coefficient equal to or higher than $95 \%$ to the inoculated strain were considered as being identical.

\section{Cholesterol Determination in Culture Medium and Cheese}

Sample Preparation. For the in vitro tests, the cells were removed after the incubation period by centrifugation $\left(8,000 \times g, 10 \mathrm{~min}, 4^{\circ} \mathrm{C}\right)$, and the spent broth and uninoculated control broth were then as- 
sayed for their cholesterol content using the method of Fletouris et al. (1998) with modifications. Briefly, an aliquot $(2 \mathrm{~mL})$ of the supernatant was mixed with $5 \mathrm{~mL}$ of methanolic $\mathrm{KOH} 0.5 \mathrm{~mol} / \mathrm{L}$ (Carlo Erba Reagents, Milan, Italy) and an internal standard solution of squalene $\quad(2,6,10,15,19,23$-hexamethyl-2,6,10,14,18,22tetracosa-hexaene; Sigma). The final squalene concentration was $24 \mu \mathrm{g} / \mathrm{mL}$. The tubes were capped tightly, and the content was vortexed for $15 \mathrm{~s}$. The lower half of the tube was heated at $80^{\circ} \mathrm{C}$ for $15 \mathrm{~min}$, and the tube was removed every $5 \mathrm{~min}$ to vortex for $10 \mathrm{~s}$. The tube was cooled; then, $1 \mathrm{~mL}$ of distilled water and $5 \mathrm{~mL}$ of hexane (Merck) were added, and the content was vortexed vigorously for $1 \mathrm{~min}$ and then centrifuged at $2,000 \times g$ for $1 \mathrm{~min}$ at $37^{\circ} \mathrm{C}$. An aliquot of the upper phase was diluted with hexane for a final volume of 1 $\mathrm{mL}$ and injected $(1 \mu \mathrm{L})$ into the GC.

The cholesterol level in the cheese was determined on the lipid fraction. About $44 \mathrm{mg}$ of fat extracted from the cheeses was accurately weighed into a vial to which $1 \mathrm{~mL}$ of hexane, $50 \mu \mathrm{L}$ of internal standard solution of squalene $(24 \mu \mathrm{g} / \mathrm{mL})$, and $50 \mu \mathrm{L}$ of methanolic $\mathrm{NaOCH}_{3} 2 M$ (sodium methoxide; Sigma) were added. The samples were vortexed for $3 \mathrm{~min}$ and then centrifuged for 1 min at $2,000 \times g$ at $37^{\circ} \mathrm{C}$. A small amount of $\mathrm{HNaSO}_{4} \cdot \mathrm{H}_{2} \mathrm{O}$ (sodium hydrogen sulfate monohydrate; Sigma) was added. The samples were further vortexed for $3 \mathrm{~min}$ and then centrifuged for $1 \mathrm{~min}$ at 2,000 $\times \mathrm{g}$ at $37^{\circ} \mathrm{C}$. An aliquot of the upper phase was diluted with hexane for a final volume of $1 \mathrm{~mL}$ and injected $(1 \mu \mathrm{L})$ into the GC.

GC-Flame Ionization Detector (GC-FID). This analysis was performed using a Varian (Palo Alto, CA) model 3300 gas chromatograph fitted with a flame ionization detector, split/splitless injector, and an SPB-1 capillary column $(30 \mathrm{~m} \times 0.32 \mathrm{~mm}$ i.d., 0.25 $\mu \mathrm{m}$ film thickness; Supelco, Bellefonte, PA) and helium as the carrier gas $(2 \mathrm{~mL} / \mathrm{min})$. Injector and detector temperatures were 250 and $300^{\circ} \mathrm{C}$, respectively. The initial oven temperature was $50^{\circ} \mathrm{C}$ and was increased by $20^{\circ} \mathrm{C} / \mathrm{min}$ to $230^{\circ} \mathrm{C}$, then by $4^{\circ} \mathrm{C} / \mathrm{min}$, and then held at $250^{\circ} \mathrm{C}$ for $25 \mathrm{~min}$. Data processing was performed using AZUR V5.0 software (Analytical Technology, Brugherio, Italy). The concentration of cholesterol was calculated using the internal standard method. All assays were repeated in triplicate.

\section{Sensory Analysis and Overall Acceptability}

To evaluate consumer-perceived quality differences, the experimental cheeses were scored for their overall acceptability as well as for appearance, taste, aroma, and texture after 30 and $60 \mathrm{~d}$ of ripening. The cheese samples (10-15 g) were assessed by a panel of 8 judges (members of the research institute) using a standard 5 -point hedonic scale, where $5=$ excellent, $4=$ very good, 3 = good, 2 = satisfactory, and $1=$ unsatisfactory. In addition, judges were required to point out defects (Lutchmedial et al., 2004).

\section{Statistical Analysis}

All data are presented as means $( \pm \mathrm{SD})$ of at least 3 independent experiments; each experiment had 3 replicates of each sample. For comparing samples, data were analyzed by ANOVA and Tukey's test for multiple pairwise comparison. Statistical calculations were performed with GraphPad Prism version 5.0 (GraphPad Software for Science Inc., San Diego, CA). A difference of $P<0.05$ was considered significant.

\section{RESULTS}

\section{Screening for LAB with Efficient Cholesterol- Lowering Ability}

The experimental results revealed different ability levels in removing cholesterol from the growth medium. In the presence of bile salts and during static growth, all strains appeared stable and vital after the incubation, their cell count in broth being higher than $10^{7}$ $\mathrm{cfu} / \mathrm{mL}$ (data not shown). Bile tolerance and the ability to assimilate cholesterol were considered primary characteristics to select potential probiotic strains with a cholesterol-lowering effect.

With the exception of $L b$. casei BT147, all the LAB strains consumed cholesterol from the medium during static growth in MRS or M17 after $24 \mathrm{~h}$ of incubation in the presence of bile salts, but there was a wide variation in the cholesterol-reducing ability among and within the species (Figures 1, 2, 3, and 4). The lowest reduction in cholesterol was brought about by Lc. lactis ssp. lactis, whereas Lb. plantarum and Lb. paracasei ssp. paracasei gave the highest decrease. The $7 \mathrm{Lb}$. casei strains lowered the cholesterol content by an average of $22.8 \pm 16.6 \%$, but, interestingly, one (VC199) reduced it with a mean percentage of approximately $54 \%$ (Figure 1).

Lactobacillus paracasei ssp. paracasei lowered the cholesterol content by an average of $26.0 \pm 10.4 \%$. Among the $27 \mathrm{Lb}$. paracasei ssp. paracasei strains, SE160 and VC213 showed the lowest cholesterol content after incubation, with mean reduction percentages of 55 and $45 \%$, respectively (Figure 2). The $L b$. plantarum strains $(\mathrm{n}=15)$ possessed a cholesterol-lowering activity comparable with $L b$. paracasei ssp. paracasei, with 


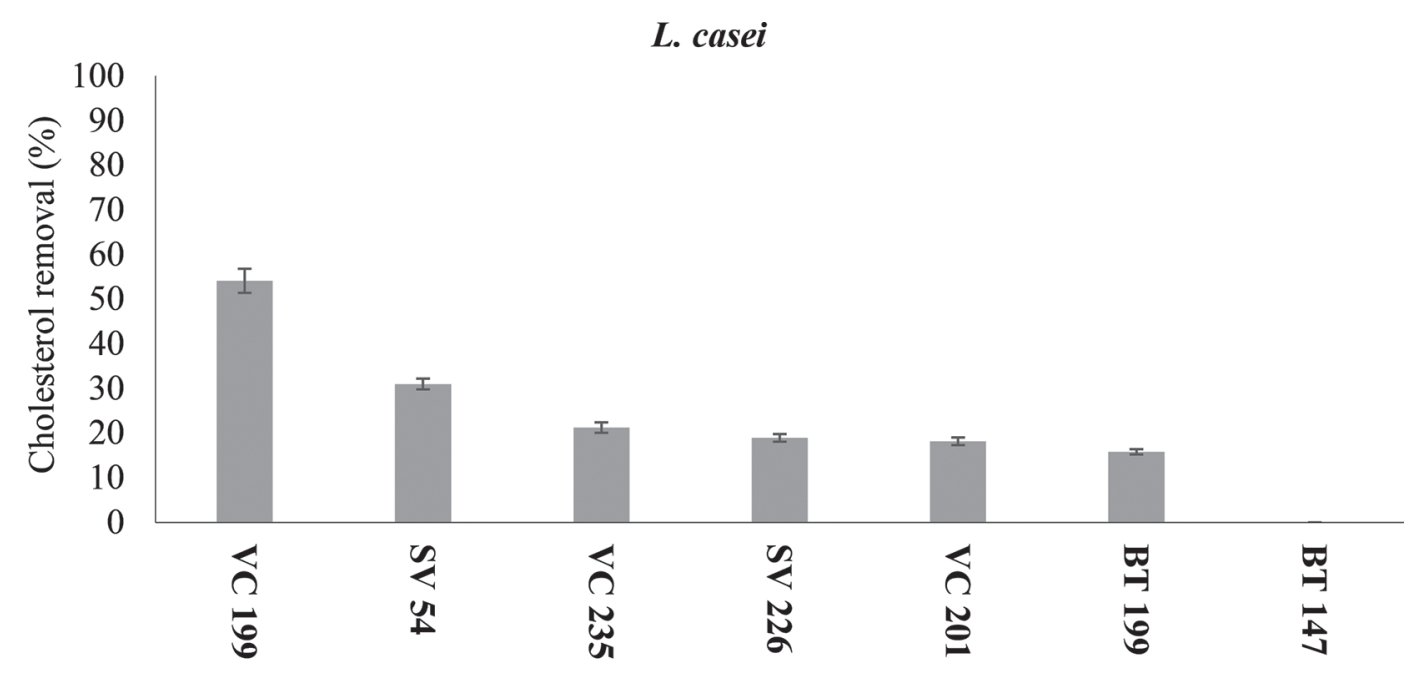

Strain

Figure 1. Cholesterol removal (\%) of 7 Lactobacillus casei strains incubated in de Man, Rogosa and Sharpe broth (Biolife, Milan, Italy) supplemented with $120 \mu \mathrm{g} / \mathrm{mL}$ of water-soluble cholesterol, $0.2 \%$ sodium thioglycolate, and $0.3 \%$ oxgall for $24 \mathrm{~h}$ at $30^{\circ} \mathrm{C}$ in anaerobic conditions. Data are shown as means $\pm \mathrm{SD}$ of triplicate measurements.

an average of $26.1 \pm 14.2 \%$, but 2 strains (VS166 and VS513) exhibited higher activity, with a mean reduction of 55 and $47 \%$, respectively (Figure 3). Enterococcus faecium $\mathrm{VC} 223$ and E. lactis BT161 lowered the cholesterol content by 45 and $42 \%$, respectively (Figure 4). Lactococcus lactis ssp. lactis was the species showing the lowest activity; in fact, none of the 7 strains were able to reduce the cholesterol content more than $30 \%$ (Figure 4).

\section{In Vitro Tests for Gastrointestinal Survival}

Seven strains resulting in more than $40 \%$ reduction of the cholesterol content in the culture medium ( $L b$. casei VC199, Lb. paracasei ssp. paracasei SE160 and VC213, Lb. plantarum VS513 and VS166, E. faecium $\mathrm{VC} 223$, and E. lactis BT161) were further analyzed for their probiotic properties. The viable cells of each LAB strain were enumerated after sequential incubation in conditions simulating the gastrointestinal tract. All 7 LAB showed resistance to, and the ability to survive, the presence of the proteolytic enzymes and low $\mathrm{pH}$ values prevailing in the stomach, the bile salts, and the pancreatic juices of the small intestine (Table 1). They did not undergo lysis in the presence of lysozyme, and when exposed to pepsin and stomach-like acidity $(\mathrm{pH}$ 3) for $90 \mathrm{~min}$, survival was greater than $96 \%$. Finally, the LAB strains proved to be resistant to bile salts and pancreatin, as the overall viability rate after exposure to small intestine conditions was in the range of 94 to $99.4 \%$ (Table 1).

\section{Cholesterol Removal from Cheese}

The 7 strains showing the highest activity in the in vitro test were further examined for their suitability, viability, and cholesterol-lowering capacity in cheese. Two experimental cheese-makings were conducted with each adjunct culture, and the cheeses were analyzed after 30 and 60 ripening days. All $7 \mathrm{LAB}$ had the capability to reduce cholesterol in cheese, although to a lower extent than in broth. In the 30-d ripened cheeses, cholesterol was present in reduced amount in those cheeses with added single test strains (Table 2). The differences were significant $(P<0.05)$ in the cheeses where the adjunct strains were inoculated, the greatest reductions being observed for Lb. plantarum VS513 (21\%), Lb. paracasei ssp. paracasei $\mathrm{VC} 213$ (18\%), E. faecium VC223 (17\%), and Lb. casei VC199 (16\%). Differences in cholesterol content of the control cheeses can be attributed to the changes naturally occurring in goat milk composition due to diet variation (Morand-Fehr et al., 2007).

For the up to 60-d ripening, there was a further reduction in cholesterol content in all the cheeses, the only exception being that produced by the addition $L b$. plantarum VS166 and VS513, where it changed insignificantly (Table 2). Instead, there were significant differences $(P<0.05)$ in the cholesterol level between 30 and $60 \mathrm{~d}$ of ripening in both the control cheeses $(2$ and 3 ) and the cheeses produced with $L b$. paracasei ssp. paracasei SE160, E. lactis BT161, and E. faecium VC223. The data indicate that over the ripening time the starter itself, along with the microorganisms naturally 


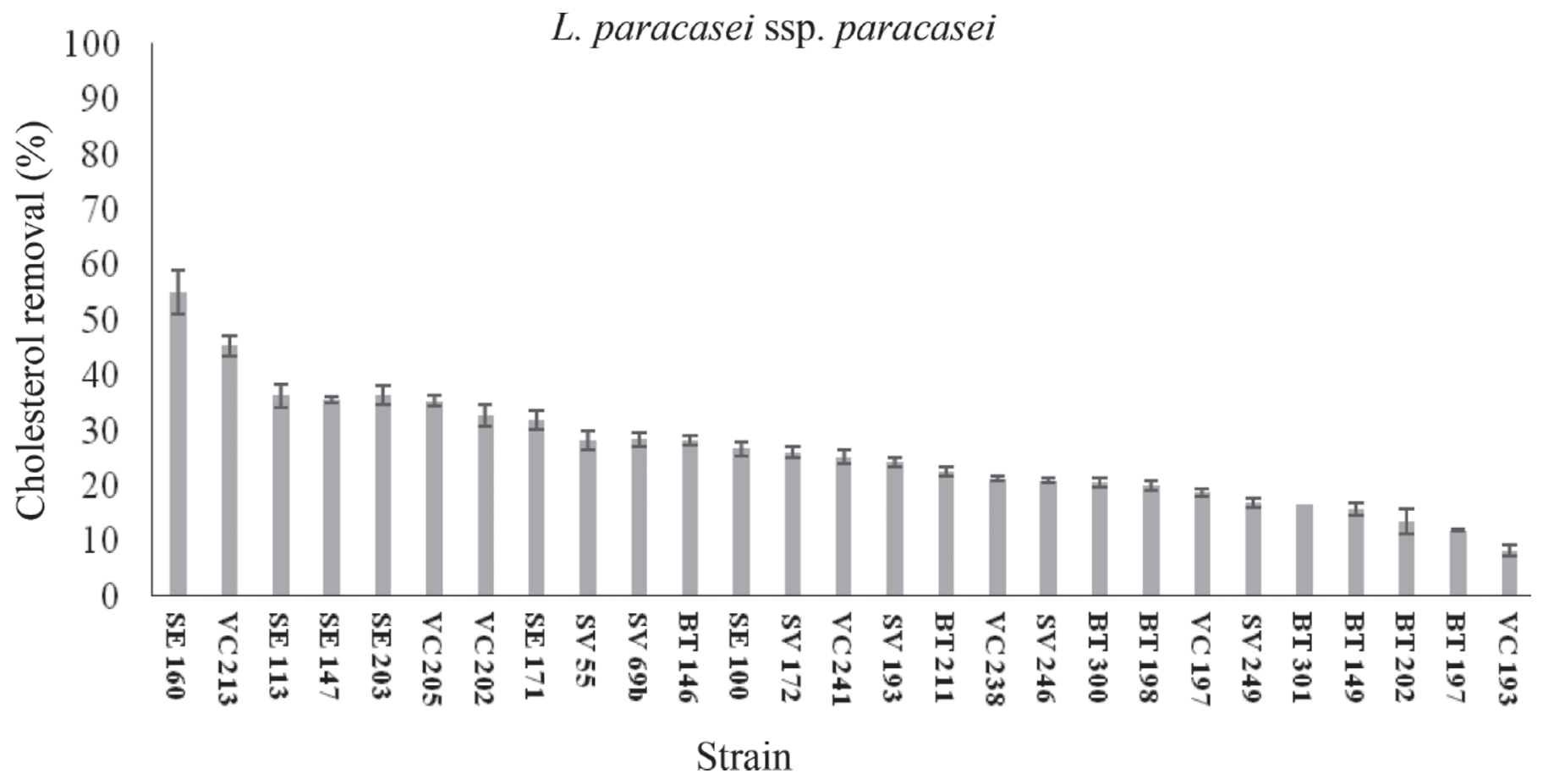

Figure 2. Cholesterol removal (\%) of 27 Lactobacillus paracasei ssp. paracasei strains incubated in de Man, Rogosa and Sharpe broth (Biolife, Milan, Italy) supplemented with $120 \mu \mathrm{g} / \mathrm{mL}$ of water-soluble cholesterol, $0.2 \%$ sodium thioglycolate, and $0.3 \%$ oxgall for $24 \mathrm{~h}$ at $30^{\circ} \mathrm{C}$ in anaerobic conditions. Data are shown as means $\pm \mathrm{SD}$ of triplicate measurements.

present in the cheese, exerts an influence on cholesterol reduction, an effect that can be significantly enhanced by specific LAB strains. After $60 \mathrm{~d}$ of ripening, the cholesterol content was significantly lower in all the cheeses produced with the adjunct of the cholesterol-lowering LAB strains than in the controls, with the exception of $L b$. plantarum VS166. The highest reductions were obtained when $L b$. paracasei ssp. paracasei $\mathrm{VC} 213$ and E. lactis BT161 were added.

\section{Cell Viability in Cheese}

Microbiological analysis of the cheeses was used to evaluate LAB strain persistence for up to $60 \mathrm{~d}$ of ripening, and RAPD PCR was carried out to control whether, and to what level, selected LAB strains can sustain viability throughout ripening (Supplemental Figure S1; https://doi.org/10.3168/jds.2018-15096). Indeed, throughout the cheese ripening, the LAB were present at a level of $10^{8}$ to $10^{9} \mathrm{cfu} / \mathrm{g}$. In the controls, the LAB content was essentially stable throughout the investigation and lower than that of the corresponding cheeses with the adjunct culture; this finding might be indicative of a mutually beneficial interrelationship between the starter LAB consisting of $S$. thermophilus and $L b$. delbrueckii ssp. bulgaricus and the tested strains (Table
3). All 7 of the cholesterol-reducing LAB strains tested during cheese manufacture were reisolated after 30 and $60 \mathrm{~d}$ of ripening and were found to be highly viable throughout the period, the log count of the different strains always being higher than $8 \log \mathrm{cfu} / \mathrm{g}$ (Table 3 ).

Generally, the viable counts remained quite constant for up to $60 \mathrm{~d}$ of ripening. Only Lb. paracasei ssp. paracasei VC213 showed a marked increase in count, by more than 1 log unit during the second $30 \mathrm{~d}$ of ripening.

\section{Sensory Analysis}

Sensory analysis evidenced high rating scores $(>4)$ for all the sensory attributes, and no significant difference was found between the experimental and control cheeses (data not shown). The overall acceptability of the experimental and control cheeses was high $(4.5 \pm$ 0.24 vs. $4.35 \pm 0.14$, respectively) and did not differ significantly after 30 and $60 \mathrm{~d}$ of ripening. No flavor or texture defect was noted.

\section{DISCUSSION}

Fifty-eight LAB strains belonging to 6 species usually involved in cheese production as starter or adjunct cultures were evaluated for their cholesterol-lowering 


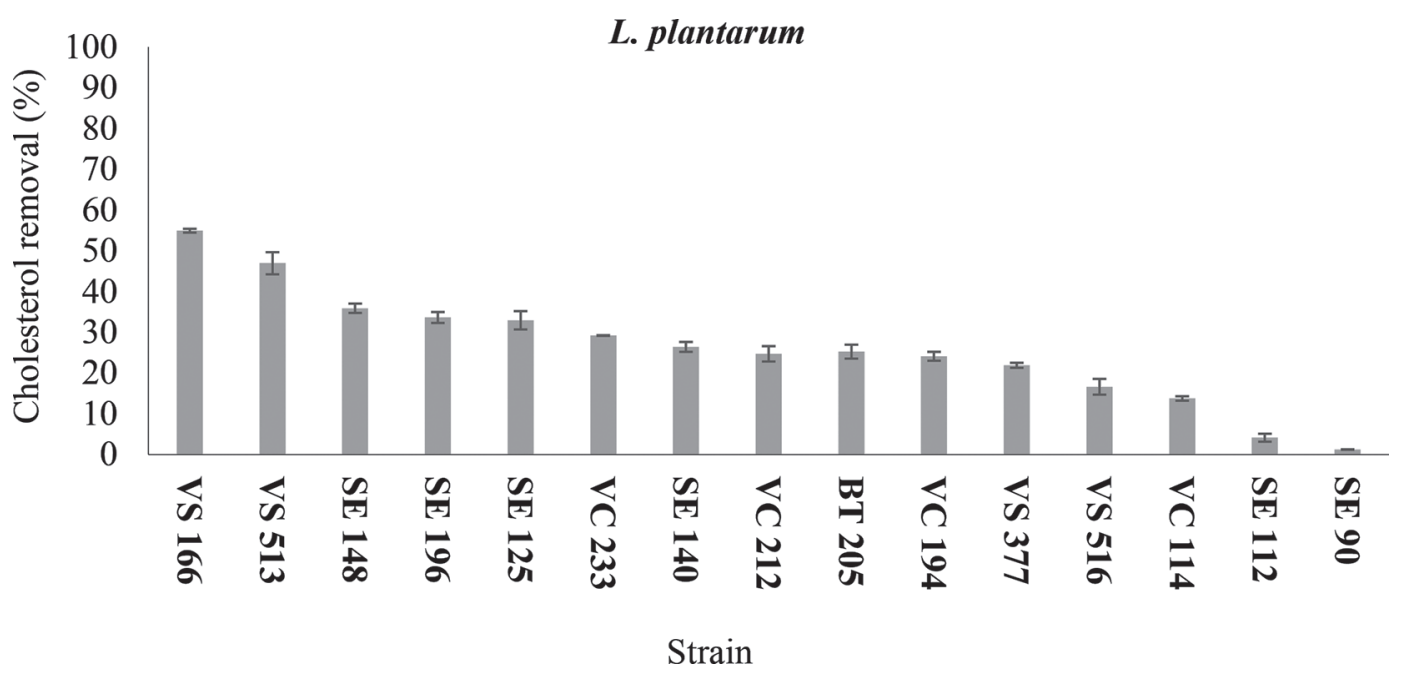

Figure 3. Cholesterol removal (\%) of 15 Lactobacillus plantarum strains incubated in de Man, Rogosa and Sharpe broth (Biolife, Milan, Italy) supplemented with $120 \mu \mathrm{g} / \mathrm{mL}$ of water-soluble cholesterol, $0.2 \%$ sodium thioglycolate, and $0.3 \%$ oxgall for $24 \mathrm{~h}$ at $30^{\circ} \mathrm{C}$ in anaerobic conditions. Data are shown as means $\pm \mathrm{SD}$ of triplicate measurements.

potential. Data related to the in vitro tests highlighted a broad diversity in the hypocholesterolemic action at both species and strain levels, confirming that each probiotic strain within each species may have different activities (Castro et al., 2016). In contrast with Pan and Zhang (2005), who found a Lc. lactis ssp. lactis strain exerting $41.83 \%$ cholesterol reduction in broth, the 7 Lc. lactis analyzed in our study were all characterized by low activity in milk, whereas $L b$. casei, $L b$. paracasei ssp. paracasei, and Lb. plantarum showed different behavior. Interestingly, the 2 enterococci strains were characterized by a reduction ability higher than $40 \%$. Seven strains out of the 58 tested demonstrated the highest removal ability in MRS/M17 broth supplemented with cholesterol and bile salts, giving rise to a noteworthy reduction of the cholesterol level in broth, ranging from 42 to $55 \%$. The strains included cocci and rods belonging to different species: $1 \mathrm{Lb}$. casei (VC199), 2 Lb. paracasei ssp. paracasei (SE160 and VC213), 2 Lb. plantarum (VS166 and VS513), 1 E. lactis (BT161), and 1 E. faecium (VC223). The cholesterol removal ratios were higher than those reported in previous studies. In fact, Pereira and Gibson (2002) evaluated in vitro the effect of human gut-derived LAB and bifidobacteria on cholesterol levels and reported that the amounts of cholesterol assimilated by the cultures ranged from 0.4 to $47 \%$ of the cholesterol added in the medium. Mishra and Prasad (2005) reported a Lb. casei strain NCDC 19 showing a decreased cholesterol content in broth of $43.2 \%$. Zeng et al. (2010) evaluated the ability of cholesterol reduction of 3 Lactobacillus buchneri strains and highlighted a wide variation among the strains.
The first had the highest cholesterol-reducing rate of $43.95 \%$, whereas the second strain reduced by $30.28 \%$ and the third showed the least at $2.73 \%$. Remagni et al. (2013) tested the cholesterol removal capacity of 58 strains of LAB belonging to Lb. plantarum, Lactobacillus acidophilus, Lb. delbrueckii ssp. bulgaricus, and Enterococcus italicus and reported that the amount of cholesterol removed from the substrate after $24 \mathrm{~h}$ ranged from a minimum of $0 \%$ to a maximum $33.31 \%$. Likewise, Lb. plantarum and Lc. lactis strains isolated from camel milk displayed a cholesterol reduction range of less than 50\% (Abushelaibi et al., 2017). Miremadi et al. (2014) highlighted a higher reduction activity for 1 Bifidobacterium longum (65\%) and $2 \mathrm{Lb}$. acidophilus (62-60\%), whereas the performance of $L b$. casei, $L b$. paracasei, and $L b$. plantarum strains was lower than that of those found in our study. In this study, 2 Enterococcus strains showed high cholesterol-removal ability $($ E. lactis $\mathrm{BT} 161=42 \%$; E. faecium $\mathrm{VC} 223=$ $45 \%$ ). The genus Enterococcus is the most controversial group of LAB. Different papers on the microbiota of many traditional Mediterranean cheeses have indicated that enterococci play an important role in the ripening of these cheeses. On the other hand, enterococci have been associated with several human infections (Foulquié Moreno et al., 2006). Recently, the assessment of E. faecium for qualified presumption of safety was performed, and this led to the conclusion that strains associated with clinical infections could be differentiated from commensal strains (EFSA Panel on Biological Hazards, 2013). The 2 strains used in this research did not harbor genes encoding for virulence factors, and 
Table 1. Survival of lactic acid bacteria strains during simulated human digestion ${ }^{1}$

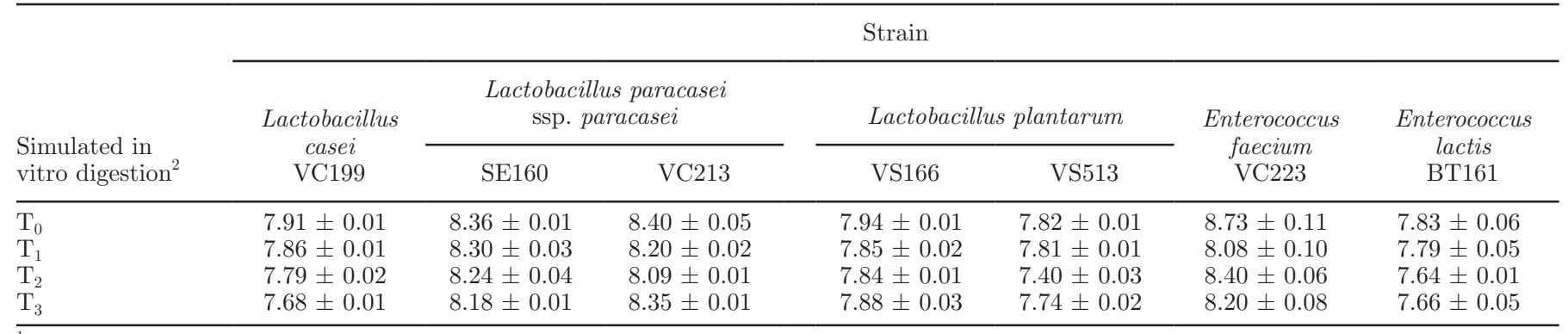

${ }^{1}$ Values are mean viable counts $\left(\log _{10} \mathrm{cfu} / \mathrm{mL}\right) \pm \mathrm{SD}$.

${ }^{2} \mathrm{~T}_{0}=$ initial inoculum; $\mathrm{T}_{1}=$ simulated hydrolysis in the human oral cavity after 5 min; $\mathrm{T}_{2}=$ simulated gastric juice after 90 min; $\mathrm{T}_{3}=$ simulated small intestine after 150 min.

antibiotic resistance was established by EFSA criteria for the safety assessment of E. faecium for intentional use in feed or food (Morandi et al., 2013, 2015), thus supporting possible use of these strains as probiotics.

The 7 best-performing LAB survived in the cheese to sufficient numbers (higher than $10^{8} \mathrm{cfu} / \mathrm{g}$ ) to potentially deliver the probiotic effect (Gomes da Cruz et al., 2009; Bhadoria and Mahapatra, 2011; Karimi et al., 2011). It is worthy of note that all the strains appeared stable and vital after $24 \mathrm{~h}$ of incubation in the presence of bile salts and under conditions mimicking the gastrointestinal tract. In fact, the first requirement for a probiotic bacterium is its ability to survive transport to the active site where its beneficial action is expected. Hence, bacteria destined to benefit intestinal functions must survive the passage through the hydrolysis in the human oral cavity, the acidic environment of the stomach, and intestinal conditions. Our results - survival rates higher than 90\% - are in agreement with those reported by other authors for other probiotic strains. Indeed, the $7 \mathrm{LAB}$ tested in this study are not sensitive to lysozyme and survive well at $\mathrm{pH} 3.0$ in the presence of pepsin (Zárate et al., 2000; Huang and Adams, 2004; Klingberg et al., 2005; Paramithiotis et al., 2006; Hosseini et al., 2009; Morandi et al., 2013). Once bacteria have survived the gastric barrier, the environment of the small intestine is the second major barrier for probiotic strains in their transit through the gastrointestinal tract. Although the $\mathrm{pH}$ of the small intestine is more favorable for bacterial survival, the presence of pancreatin and bile salts can have adverse effects. Our results indicate that the selected strains are resistant, even in the presence of bile salts, to the action of pancreatin, simulating the small intestine transit.

Thus, it can be reasonably supposed that these strains are capable of surviving in the human body and potentially remove cholesterol. Indeed, it is known that cholesterol assimilation is associated with the presence of bile salts (Tahri et al., 1996; Zeng et al.,
2010). Moreover, the survival and growth of LAB that assimilate cholesterol in the intestine are important in that it decreases dietary cholesterol absorption from
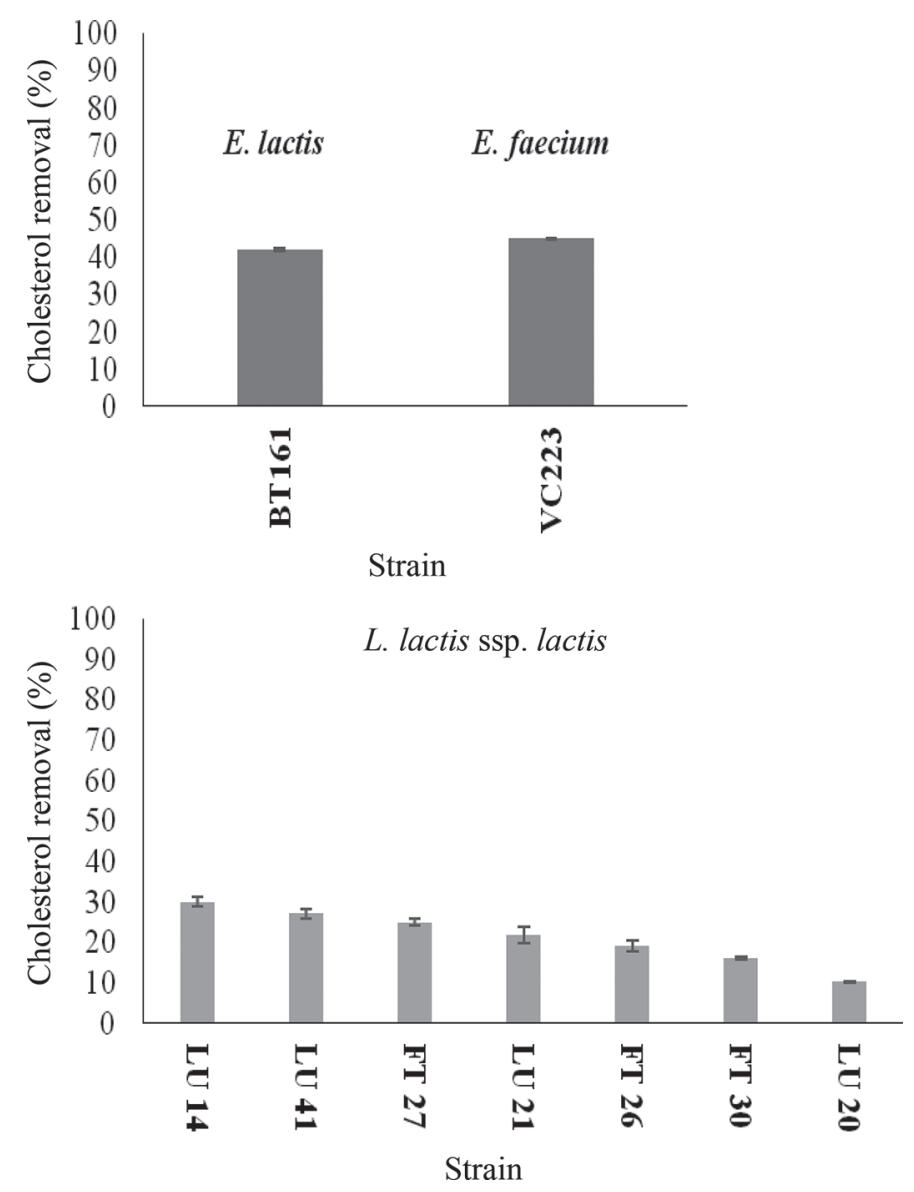

Figure 4. (Top) Cholesterol removal (\%) by Enterococcus lactis and Enterococcus faecium strains. (Bottom) Cholesterol removal (\%) by Lactococcus lactis ssp. lactis strains $(\mathrm{n}=7)$ incubated in M17 broth (Biolife, Milan, Italy) supplemented with $120 \mu \mathrm{g} / \mathrm{mL}$ of watersoluble cholesterol, $0.2 \%$ sodium thioglycolate, and $0.3 \%$ oxgall for 24 $\mathrm{h}$ at $30^{\circ} \mathrm{C}$ in anaerobic conditions. Data are shown as means $\pm \mathrm{SD}$ of triplicate measurements. 
Table 2. Cholesterol content $(\mathrm{mg} / 100 \mathrm{~g}$ of fat) in cheeses produced with cholesterol-lowering lactic acid bacteria strains during ripening time ${ }^{1}$

\begin{tabular}{|c|c|c|c|}
\hline \multirow[b]{2}{*}{ Item } & \multicolumn{2}{|c|}{ Ripening time } & \multirow[b]{2}{*}{$P$-value } \\
\hline & $30 \mathrm{~d}$ & $60 \mathrm{~d}$ & \\
\hline$\overline{\text { Control } 1}$ & $191.2 \pm 1.7^{\mathrm{b}}$ & $180.3 \pm 2.2^{\mathrm{a}}$ & NS \\
\hline Lactobacillus plantarum VS 166 & $168.4 \pm 0.5^{\mathrm{a}}(12 \%)$ & $170.7 \pm 1.1^{\mathrm{a}}(5 \%)$ & NS \\
\hline Control 2 & $230.1 \pm 13.1^{\mathrm{c}}$ & $209.0 \pm 12.0^{\mathrm{c}}$ & $* *$ \\
\hline Lactobacillus plantarum VS 513 & $182.8 \pm 0.8^{\mathrm{a}}(21 \%)$ & $190.4 \pm 0.1^{\mathrm{b}}(9 \%)$ & NS \\
\hline Lactobacillus casei VC 199 & $193.2 \pm 1.1^{\mathrm{a}}(16 \%)$ & $187.3 \pm 0.3^{\mathrm{b}}(10 \%)$ & NS \\
\hline Lactobacillus paracasei ssp. paracasei SE 160 & $210.2 \pm 0.8^{\mathrm{b}}(9 \%)$ & $186.5 \pm 1.2^{\mathrm{b}}(11 \%)$ & $* * *$ \\
\hline Lactobacillus paracasei ssp. paracasei $\mathrm{VC} 213$ & $187.9 \pm 0.6^{\mathrm{a}}(18 \%)$ & $174.7 \pm 2.9^{\mathrm{a}}(16 \%)$ & NS \\
\hline Control 3 & $310.2 \pm 2.7^{\mathrm{c}}$ & $258.2 \pm 8.1^{\mathrm{c}}$ & *** \\
\hline Enterococcus lactis BT 161 & $269.7 \pm 0.3^{\mathrm{b}}(13 \%)$ & $199.8 \pm 1.0^{\mathrm{a}}(23 \%)$ & $* * *$ \\
\hline Enterococcus faecium VC 223 & $256.7 \pm 2.4^{\mathrm{a}}(17 \%)$ & $225.6 \pm 0.6^{\mathrm{b}}(13 \%)$ & $* * *$ \\
\hline
\end{tabular}

$\overline{{ }^{a-c} \text { Means within the same experiment and column followed by different superscripts differ significantly }(P<}$ $0.05)$.

${ }^{1}$ Control cheeses are included for each experimental cheese-making. Data are expressed as mean \pm SD of triplicate determinations on 2 cheese-making trials. Reduction percentages, in parentheses, were calculated by reference to the respective controls.

${ }^{* *} P<0.01 ;{ }^{* * *} P<0.001$.

the digestive system into the blood and could thus have the potential to aid in the control of serum and liver cholesterol (Wang et al., 2012; Zanotti et al., 2015). The experimental data available today indicate that the constant consumption of probiotics can effectively reduce serum cholesterol by more than $1 \%$, thus encouraging the development of new functional foods as complementary therapy (Hlivak et al., 2005; Ding et al., 2017).

In this regard, it has to be considered that cheese and dairy products are efficient food carriers for probiotics because of their high fat content and their high buffering capacity that enhances bacterial survival through the intestinal tract (Dinakar and Mistry, 1994; Desfossés-Foucault et al., 2012). In support of this, dif- ferent studies have shown that the regular consumption of probiotic cheese and dairy products with microbial populations similar to ours can contribute to improved health by means of cardiovascular health parameters (Lollo et al., 2015), blood lipid profile and antioxidant defenses (Moura et al., 2016), the immune system (Medici et al., 2004), oxidative stress-mediated atherogenicity (Kullisaar et al., 2003), and cholesterol-lowering efficacy (Ooi and Liong, 2010; Ding et al., 2017).

Another interesting aspect to consider is the possibility of reducing the cholesterol content in the food matrix itself by means of LAB. To date, only a few studies are available on the cholesterol-lowering activity of LAB in dairy products. Belviso et al. (2009) reported 2 Lb. plantarum removing cholesterol in milk (up to

Table 3. Bacterial counts $(\log \mathrm{cfu} / \mathrm{g})$ in the experimental cheeses during ripening time $(30 \text { or } 60 \mathrm{~d})^{1}$

\begin{tabular}{|c|c|c|c|c|c|c|}
\hline \multirow[b]{2}{*}{ Test strain } & \multicolumn{3}{|c|}{$\begin{array}{l}\text { Total lactic acid bacteria } \\
\text { present in experimental cheeses }\end{array}$} & \multicolumn{3}{|c|}{$\begin{array}{l}\text { Cholesterol-removing strain added } \\
\text { to experimental cheeses }\end{array}$} \\
\hline & $30 \mathrm{~d}$ & $60 \mathrm{~d}$ & $P$-value & $30 \mathrm{~d}$ & $60 \mathrm{~d}$ & $P$-value \\
\hline Lactobacillus plantarum VS 166 & $9.1 \pm 0.0$ & $8.9 \pm 0.3$ & NS & $8.5 \pm 0.2$ & $8.5 \pm 0.4$ & NS \\
\hline Control 2 & $8.5 \pm 0.1$ & $7.9 \pm 0.4$ & NS & & & \\
\hline Lactobacillus plantarum VS 513 & $8.6 \pm 0.2$ & $8.7 \pm 0.8$ & NS & $8.4 \pm 0.1$ & $8.4 \pm 0.3$ & NS \\
\hline Lactobacillus paracasei ssp. paracasei $\mathrm{VC} 213$ & $8.3 \pm 0.6$ & $9.4 \pm 0.0$ & NS & $7.9 \pm 0.1$ & $9.3 \pm 0.2$ & $* * *$ \\
\hline Control 3 & $8.5 \pm 0.4$ & $8.1 \pm 0.2$ & NS & & & \\
\hline Enterococcus lactis BT 161 & $8.9 \pm 0.8$ & $8.7 \pm 0.3$ & NS & $8.5 \pm 0.2$ & $8.3 \pm 0.1$ & NS \\
\hline Enterococcus faecium $\mathrm{VC} 223$ & $8.9 \pm 0.1$ & $8.9 \pm 0.2$ & NS & $8.6 \pm 0.3$ & $8.6 \pm 0.0$ & NS \\
\hline
\end{tabular}

${ }^{1}$ Data are expressed as mean \pm SD of triplicate determinations on 2 cheese-making trials. $* * * P<0.001$. 
$8.2 \%$ ) through cell wall adsorption. In our study, 7 LAB strains were shown to exert progressive cholesterollowering activity in cheese, activity greater than that reported to date (up to $21 \%$ during $60 \mathrm{~d}$ of ripening), although the strains behaved differently. Lactobacillus plantarum VS513, Lb. casei VC199, and Lb. paracasei ssp. paracasei $\mathrm{VC} 213$ reached maximum activity before the end of $30 \mathrm{~d}$ of ripening, whereas E. lactis BT161, E. faecium VC233, and Lb. paracasei $\mathrm{ssp}$. paracasei SE160 showed a further significant reduction by extending the ripening to up to $60 \mathrm{~d}$. This finding can be explained by the naturally occurring high-level persistence of enterococci and lactobacilli in cheese during ripening. The progressive reduction of the cholesterol content in the matrix indicates that cholesterol is not released during resting or in the mortality phase, and it can be reasonably supposed that it was removed through cell wall adsorption, as evidenced by other authors investigating LAB strains after their growth in culture medium (Choi and Chang, 2015).

\section{CONCLUSIONS}

Our results demonstrate that 7 potential probiotic LAB strains possess desirable properties in terms of cholesterol-lowering activity. This opens the way to their incorporation into novel functional foods; for example, they could be used for the production of probiotic cheese and other dairy products such as fermented milk or a dairy dessert with reduced cholesterol content and with interesting functional properties. Increasing consumer awareness with regard to the relationship between diet and health, and the consumption of cuttingedge foods with health benefit functions, should lead to greater real-life opportunities for both consumers and the food industry. Further studies are needed not only to explore the mechanisms by which LAB strains modulate hypocholesterolemic effects but also for a proper safety assessment to prevent potential adverse reactions. Moreover, to strengthen these proposals, in vivo studies are needed to generate more direct evidence of the cholesterol-lowering clinical efficacy of strains as a probiotic formulation or as a fermented milk or cheese, and in vivo studies could also be used to evaluate the effective dosage and frequency of treatment required to exert hypocholesterolemic effects.

\section{ACKNOWLEDGMENTS}

We thank Maria Chiara Onida ("Il Boscasso" cheese factory farm, Ruino, Pavia, Italy) for the manufacture of the goat cheese used in the study. This research was supported by the Regione Lombardia, project "Filagro."

\section{REFERENCES}

Abushelaibi, A., S. Al-Mahadin, K. El-Tarabily, N. P. Shah, and M. Ayyash. 2017. Characterization of potential probiotic lactic acid bacteria isolated from camel milk. Lebensm. Wiss. Technol. 79:316-325.

Aloğlu, H., and Z. Öner. 2006. Assimilation of cholesterol in broth, cream and butter by probiotic bacteria. Eur. J. Lipid Sci. Technol. 108:709-713.

Ayyash, M., A. Abushelaibi, S. Al-Mahadin, M. Enan, K. El-Tarabily, and N. Shah. 2018. In vitro investigation into probiotic characterisation of Streptococcus and Enterococcus isolated from camel milk. Lebensm. Wiss. Technol. 87:478-487.

Belviso, S., M. Giordano, P. Dolci, and G. Zeppa. 2009. In vitro cholesterol-lowering activity of Lactobacillus plantarum and Lactobacillus paracasei strains isolated from the Italian Castelmagno PDO cheese. Dairy Sci. Technol. 89:169-176.

Bhadoria, P. B. S., and S. C. Mahapatra. 2011. Prospects, technological aspects and limitations of probiotics - A worldwide review. Eur. J. Food Res. Rev. 1:23-42.

Bliznakov, E. G. 2002. Lipid-lowering drugs (statins), cholesterol, and coenzyme Q10. The Baycol case-A modern Pandora's box. Biomed. Pharmacother. 56:56-59.

Brasca, M., J. A. Hogenboom, S. Morandi, V. Rosi, P. D'Incecco, T. Silvetti, and L. Pellegrino. 2016. Proteolytic activity and production of $\gamma$-aminobutyric acid by Streptococcus thermophilus cultivated in microfiltered pasteurized milk. J. Agric. Food Chem. 64:8604-8614.

Castro, M. S., M. A. Molina, M. B. Azpiroz, A. M. Díaz, R. Ponzio, M. D. Sparo, M. A. Manghi, and A. M. Canellada. 2016. Probiotic activity of Enterococcus faecalis CECT 7121: Effects on mucosal immunity and intestinal epithelial cells. J. Appl. Microbiol. 121:1117-1129

Choi, E. A., and H. C. Chang. 2015. Cholesterol-lowering effects of a putative probiotic strain Lactobacillus plantarum EM isolated from kimchi. Lebensm. Wiss. Technol. 62:210-217.

Clarke, G., J. F. Cryan, T. G. Dinan, and E. M. Quigley. 2012. Review article: Probiotics for the treatment of irritable bowel syndrome - Focus on lactic acid bacteria. Aliment. Pharmacol. Ther. 35:403-413.

Collins, S. M. 2014. A role for the gut microbiota in IBS. Nat. Rev. Gastroenterol. Hepatol. 11:497-505.

Dantas, A. B., V. F. Jesus, R. Silva, C. N. Almada, E. A. Esmerino, L. P. Cappato, and A. S. Sant'Ana. 2016. Manufacture of probiotic Minas Frescal cheese with Lactobacillus casei Zhang. J. Dairy Sci. 99:18-30.

Desfossés-Foucault, E., V. Dussault-Lepage, C. Le Boucher, P. Savard, G. La Pointe, and D. Roy. 2012. Assessment of probiotic viability during Cheddar cheese manufacture and ripening using propidium monoazide-PCR quantification. Front. Microbiol. 3:350.

Dinakar, P., and V. V. Mistry. 1994. Growth and viability of Bifidobacterium longum in Cheddar cheese. J. Dairy Sci. 77:2854-2864.

Ding, W., C. Shi, M. Chen, J. Zhou, R. Long, and X. Guo. 2017. Screening for lactic acid bacteria in traditional fermented Tibetan yak milk and evaluating their probiotic and cholesterol-lowering potentials in rats fed a high-cholesterol diet. J. Funct. Foods 32:324-332.

EFSA Panel on Additives and Products or Substances used in Animal Feed (FEEDAP). 2012. Guidance on the safety assessment of Enterococcus faecium in animal nutrition. EFSA J. 10:2682.

EFSA Panel on Biological Hazards. 2013. Scientific opinion on the maintenance of the list of QPS biological agents intentionally added to food and feed (2013 update). EFSA J. 11:3449.

EFSA Panel on Additives and Products or Substances Used in Animal Feed. 2012. Guidance on the assessment of bacterial susceptibility to antimicrobials of human and veterinary importance. EFSA J. 10:2740.

Fletouris, D. J., N. A. Botsoglou, E. I. Psomas, and A. I. Mantis. 1998. Rapid determination of cholesterol in milk and milk products by direct saponification and capillary gas chromatography. J. Dairy Sci. 81:2833-2840. 
Foulquié Moreno, M. F., P. Sarantinopoulos, E. Tsakalidou, and L. De Vuyst. 2006. The role and application of enterococci in food and health. Int. J. Food Microbiol. 106:1-24.

Gomes da Cruz, A., F. C. A. Buriti, C. H. Batista de Souza, J. A. F. Faria, and S. M. I. Saad. 2009. Probiotic cheese: Health benefits, technological and stability aspects. Trends Food Sci. Technol. 20:344-354.

Guarcello, R., S. Carpino, R. Gaglio, A. Pino, T. Rapisarda, C. Caggia, G. Marino, C. L. Randazzo, L. Settanni, and M. Todaro. 2016. A large factory-scale application of selected autochthonous lactic acid bacteria for PDO Pecorino Siciliano cheese production. Food Microbiol. 59:66-75.

Han, E. M., S. H. Kim, J. Ahn, and H. S. Kwak. 2007. Optimizing cholesterol removal from cream using $\beta$-cyclodextrin cross-linked with adipic acid. Int. J. Dairy Technol. 60:31-36.

Hlivak, P., J. Odraska, M. Ferencik, L. Ebringer, E. Jahnova, and Z. Mikes. 2005. One-year application of probiotic strain Enterococcus faecium M-74 decreases serum cholesterol levels. Bratisl. Lek Listy 106:67-72.

Hosseini, S. V., S. Arlindo, K. Böhme, C. Fernández-No, P. CaloMata, and J. Barros-Velázquez. 2009. Molecular and probiotic characterization of bacteriocin-producing Enterococcus faecium strains isolated from non-fermented animal foods. J. Appl. Microbiol. 107:1392-1403.

Huang, Y., and M. C. Adams. 2004. In vitro assessment of the upper gastrointestinal tolerance of potential probiotic dairy propionibacteria. Int. J. Food Microbiol. 91:253-260.

Ishimwe, N., E. B. Daliri, B. H. Lee, F. Fang, and G. Du. 2015. The perspective on cholesterol-lowering mechanisms of probiotics. Mol. Nutr. Food Res. 59:94-105.

Jeong, J. H., C. Y. Lee, and D. K. Chung. 2016. Probiotic lactic acid bacteria and skin health. Crit. Rev. Food Sci. Nutr. 56:2331-2337.

Kanmani, P., R. Satish Kumar, N. Yuvaraj, K. A. Paari, V. Pattukumar, and V. Arul. 2013. Probiotics and its functionally valuable products-A review. Crit. Rev. Food Sci. Nutr. 53:641-658.

Karimi, R., A. Mortazavian, and C. Adrano. 2011. Viability of probiotic microorganisms in cheese during production and storage: $\mathrm{A}$ review. Dairy Sci. Technol. 91:283-308.

Kimoto, H., S. Ohmomo, and T. Okamoto. 2002. Cholesterol removal from media by lactococci. J. Dairy Sci. 85:3182-3188.

Klaver, F. A., and R. Van Der Meer. 1993. The assumed assimilation of cholesterol by Lactobacilli and Bifidobacterium bifidum is due to their bile salt-deconjugating activity. Appl. Environ. Microbiol. 59:1120-1124.

Klingberg, T. D., L. Axelsson, K. Naterstad, D. Elsser, and B. B. Budde. 2005. Identification of potential probiotic starter cultures for Scandinavian-type fermented sausages. Int. J. Food Microbiol. 105:419-431.

Kullisaar, T., E. Songisepp, M. Mikelsaar, K. Zilmer, T. Vihalemm, and M. Zilmer. 2003. Antioxidative probiotic fermented goats' milk decreases oxidative stress-mediated atherogenicity in human subjects. Br. J. Nutr. 90:449-456.

Kumar, M., R. Nagpal, R. Kumar, R. Hemalatha, V. Verma, A. Kumar, C. Chakraborty, B. Singh, F. Marotta, S. Jain, and H. Yaday. 2012. Cholesterol-lowering probiotics as potential biotherapeutics for metabolic diseases. Exp. Diabetes Res. 2012:902917.

Larsen, J. E., and G. W. Froning. 1981. Extraction and processing of various components from egg yolk. Poult. Sci. 60:160-167.

Law, M. 2000. Plant sterol and stanol margarines and health. BMJ 320:861-864

Liong, M. T., and N. P. Shah. 2005. Optimization of cholesterol removal by probiotics in the presence of prebiotics by using a response surface method. Appl. Environ. Microbiol. 71:1745-1753.

Liu, L. 2007. Cardiovascular diseases in China. Biochem. Cell Biol. 85:157-163.

Lollo, P. C., P. N. Morato, C. S. Moura, C. N. Almada, T. L. Felicio, E. A. Esmerino, M. E. Barros, J. Amaya-Farfan, A. S. Sant'Ana, R. R. Raices, M. C. Silva, and A. G. Cruz. 2015. Hypertension parameters are attenuated by the continuous consumption of probiotic Minas cheese. Food Res. Int. 76:611-617.
Lutchmedial, M., R. Ramlal, N. Badrie, and I. Chang-Yen. 2004. Nutritional and sensory quality of stirred soursop (Annona muricata L.) yoghurt. Int. J. Food Sci. Nutr. 55:407-414.

Lye, H. S., G. Rusul, and M. T. Liong. 2010. Removal of cholesterol by lactobacilli via incorporation and conversion to coprostanol. J. Dairy Sci. 93:1383-1392.

Mann, G. V., and A. Spoerry. 1974. Studies of a surfactant and cholesteremia in the Maasai. Am. J. Clin. Nutr. 27:464-469.

Manson, J. E., H. Tosteson, P. M. Ridker, S. Satterfield, P. Herbert, and G. T. O'Conner. 1992. The primary prevention of myocardial infarction. N. Engl. J. Med. 326:1406-1416.

McCabe, K. M., Y. H. Zhang, G. Khan, E. O. Mason, and E. R. B. McCabe. 1995. Amplification of bacterial DNA using highly conserved sequences: Automated analysis and potential for molecular triage of sepsis. Pediatrics 95:165-169.

Medici, M., C. G. Vinderola, and G. Perdigón. 2004. Gut mucosal immunomodulation by probiotic fresh cheese. Int. Dairy J. 14:611618.

Miremadi, F., M. Ayyash, and F. Sherkat. 2014. Cholesterol reduction mechanisms and fatty acid composition of cellular membranes of probiotic Lactobacilli and Bifidobacteria. J. Funct. Foods 9:295305.

Mishra, V., and D. N. Prasad. 2005. Application of in vitro methods for selection of Lactobacillus casei strains as potential probiotics. Int. J. Food Microbiol. 103:109-115.

Morand-Fehr, P., V. Fedele, M. Decandia, and Y. Le Frileux. 2007. Influence of farming and feeding systems on composition and quality of goat and sheep milk. Small Rumin. Res. 68:20-34.

Morandi, S., T. Silvetti, and M. Brasca. 2013. Biotechnological and safety characterization of Enterococcus lactis, a recently described species of dairy origin. Antonie van Leeuwenhoek 103:239-249.

Morandi, S., T. Silvetti, J. M. Miranda Lopez, and M. Brasca. 2015. Antimicrobial activity, antibiotic resistance and the safety of lactic acid bacteria in raw milk Valtellina Casera cheese. J. Food Saf. 35:193-205.

Moura, C. S., P. C. B. Lollo, P. N. Morato, E. A. Esmerino, L. P. Margalho, V. A. Santos-Junior, P. T. Coimbra, L. P. Cappato, M. C. Silva, A. S. Garcia-Gomes, D. Granato, H. M. A. Bolini, A. S. Sant'Ana, A. G. Cruz, and J. Amaya-Farfan. 2016. Assessment of antioxidant activity, lipid profile, general biochemical and immune system responses of Wistar rats fed with dairy dessert containing Lactobacillus acidophilus La-5. Food Res. Int. 90:275-280.

Nueno-Palop, C., and A. Narbad. 2011. Probiotic assessment of Enterococcus faecalis CP58 isolated from human gut. Int. J. Food Microbiol. 145:390-394.

Ooi, L. G., and M. T. Liong. 2010. Cholesterol-lowering effects of probiotics and prebiotics: A review of in vivo and in vitro findings. Int. J. Mol. Sci. 11:2499-2522.

Pan, D., and D. Zhang. 2005. Screening of cholesterol-reducing lactic acid bacteria and its activity in cholesterol reducing. Food Sci. $26: 233-237$.

Paramithiotis, S., I. Melissari, and E. H. Drosinos. 2006. In vitro assessment of properties associated with the survival through the gastro-intestinal tract of staphylococci isolated from traditional sausage fermentation. Food Microbiol. 23:663-671.

Pereira, D. I. A., and G. R. Gibson. 2002. Cholesterol assimilation by lactic acid bacteria and bifidobacteria isolated from the human gut. Appl. Environ. Microbiol. 68:4689-4693.

Puska, P., S. Mendis, B. Norrving, and World Health Organization. 2011. Global Atlas on Cardiovascular Disease Prevention and Control. World Health Organization, Geneva, Switzerland.

Remagni, M. C., M. Paladino, F. Locci, F. V. Romeo, M. Zago, M. Povolo, G. Contarini, and D. Carminati. 2013. Cholesterol removal capability of lactic acid bacteria and related cell membrane fatty acid modifications. Folia Microbiol. (Praha) 58:443-449.

Shaper, A. G., K. W. Jones, and J. Kyobe. 1963. Serum lipids in the three nomadic tribes of Northern Kenya. Am. J. Clin. Nutr. 13:135-146.

Tahri, K., J. P. Grill, and F. Schnider. 1996. Bifidobacteria strain behaviour towards cholesterol: Coprecipitation with bile salts and assimilations. Curr. Microbiol. 33:187-193. 
Townsend, N., L. Wilson, P. Bhatnagar, K. Wickramasinghe, M. Rayner, and M. Nichols. 2016. Cardiovascular disease in Europe: Epidemiological update 2016. Eur. Heart J. 37:3232-3245.

Usman, and A. Hosono. 1999. Bile tolerance, taurocholate deconjugation, and binding of cholesterol by Lactobacillus gasseri strains. J. Dairy Sci. 82:243-248.

Vinderola, C. G., W. Prosello, D. Ghiberto, and J. A. Reinheimer. 2000. Viability of probiotic (Bifidobacterium, Lactobacillus acidophilus and Lactobacillus casei) and nonprobiotic microflora in Argentinian Fresco cheese. J. Dairy Sci. 83:1905-1911.

Vizoso Pinto, M. G., C. M. Franz, U. Schillinger, and W. H. Holzapfel. 2006. Lactobacillus spp. with in vitro probiotic properties from human faeces and traditional fermented products. Int. J. Food Microbiol. 109:205-214.

Wang, J., H. Zhang, X. Chen, Y. Chen, and Q. Bao. 2012. Selection of potential probiotic lactobacilli for cholesterol-lowering properties and their effect on cholesterol metabolism in rats fed a high-lipid diet. J. Dairy Sci. 95:1645-1654.
Zanotti, I., F. Turroni, A. Piemontese, L. Mancabelli, C. Milani, A Viappiani, G. Prevedini, B. Sanchez, A. Margolles, L. Elviri, B. Franco, D. van Sinderen, and M. Ventura. 2015. Evidence for cholesterol-lowering activity by Bifidobacterium bifidum PRL2010 through gut microbiota modulation. Appl. Microbiol. Biotechnol. 99:6813-6829.

Zárate, G., A. P. Chaia, S. González, and G. Oliver. 2000. Viability and $\beta$-galactosidase activity of dairy propionibacteria subjected to digestion by artificial gastric and intestinal fluids. J. Food Prot. 63:1214-1221.

Zeng, X. Q., D. D. Pan, and Y. X. Guo. 2010. The probiotic properties of Lactobacillus buchneri P2. J. Appl. Microbiol. 108:2059-2066.

Zhong, L., X. Zhang, and M. Covasa. 2014. Emerging roles of lactic acid bacteria in protection against colorectal cancer. World J. Gastroenterol. 20:7878-7886. 